\title{
THE TREATMENT OF THE MACROCYTIC ANAEMIAS
}

\author{
By Ronald H. Girdwood, M.B., Ch.B., F.R.C.P.(Ed.), M.R.C.P.(Lond.) \\ Lecturer in Medicine, University of Edinburgh
}

Anaemia is said to be macrocytic when the mean corpuscular volume is greater than $95 \mathrm{cu}$. microns. The macrocytosis may occur in conjunction with a megaloblastic bone marrow, as in pernicious anaemia, a macronormoblastic marrow, as sometimes occurs in chronic hepatic cirrhosis, or a normoblastic marrow as in certain forms of haemolytic anaemia.

Most haematologists in this country use the terminology of Israëls (1939, 194I), or a modification of this terminology, and recognize in truly megaloblastic forms of anaemia three stages after the proerythroblast in the development of the abnormal red cell precursor. The cells in these stages are frequently referred to as early, intermediate and late megaloblasts, and excellent illustrations of these are available in the textbook by Whitby and Britton (1950).

In addition, however, in certain conditions where megaloblastosis typically occurs, it is not uncommon to find that in some patients the marrow contains not true megaloblasts, but cells with an appearance intermediate between that of the megaloblast and that of the normoblast. There

TABLe I

Classification of the Macrocytic Anaemias

\begin{tabular}{|c|c|c|c|}
\hline . & \multicolumn{3}{|c|}{$\begin{array}{l}\text { Marrow pictures that have been reported in } \\
\text { association with macrocytic anaemia }\end{array}$} \\
\hline . & $\begin{array}{l}\text { Megalo- } \\
\text { blastic }\end{array}$ & $\begin{array}{l}\text { Cells intermediate } \\
\text { between megaloblasts } \\
\text { and normoblasts }\end{array}$ & $\begin{array}{l}\text { Normoblastic } \\
\text { or macro- } \\
\text { normoblastic }\end{array}$ \\
\hline $\begin{array}{l}\text { Pernicious anaemia in relapse } \\
\text { Nutritional macrocytic anaemia } \\
\text { Sprue tropical } \\
\text { "' non-tropical } \\
\text { Meeliac disease } \\
\text { 'Megaloblastic' anaemia of pregnancy and the puerperium } \\
\text { Megaloblastic anaemia associated with intestinal strictures, } \\
\text { operations and lacteal blockage } \\
\text { Diphyllobothrium latum infestation } \\
\text { Achrestic anaemia and idiopathic refractory megaloblastic } \\
\text { anaemia } \\
\text { Megaloblastic anaemia inadequately treated } \\
\text { Leukaemia } \\
\text { Haemolytic anaemia } \\
\text { Hepatic cirrhosis } \\
\text { Multiple myeloma, carcinomatosis and reticulosis } \\
\text { After haemorrhage } \\
\text { Myxoedema } \\
\text { Scurvy } \\
\text { Chronic nephritis } \\
\text { Osteosclerosis } \\
\text { Chronic infections }\end{array}$ & $\begin{array}{c}+ \\
+ \\
+ \\
+ \\
+ \\
+ \\
+ \\
+ \\
+ \\
+ \\
+ \\
+ \\
\text { (rare) } \\
+ \\
\text { (very rare } \\
\text { during crisis) } \\
+ \\
\text { (rare) }\end{array}$ & $\begin{array}{l}+ \\
+ \\
+ \\
+ \\
+ \\
+ \\
+ \\
+\end{array}$ & $\begin{array}{r}+ \\
+ \\
+ \\
+ \\
+ \\
+ \\
+ \\
+ \\
+ \\
+ \\
+\end{array}$ \\
\hline
\end{tabular}


is no satisfactory name for these cells, which have been variously called ' macroblasts,' ' megalonormoblasts' and 'intermediate erythroblasts.' Unfortunately, however, Dacie and White (1949) refer to such cells as 'intermediate megaloblasts,' thus using a term that most haematologists reserve for a stage in the development of cells of the true megaloblast series.

Macronormoblastic erythropoiesis differs from the type considered in the last paragraph in that the red cell precursors, although larger than usual, have nuclear structure similar to that of the normoblast. Actual measurements of the size of the marrow cells have been carried out by Dameshek and Schwartz (1940) and by Dacie and White (1949):

It is possible to put forward a classification of the commoner macrocytic anaemias as given in Table I.

Construction of such a table is difficult owing to the confused state of the literature with regard to bone marrow findings, the fact that many investigators have been content to classify the cells merely as megaloblasts and normoblasts, and the almost complete absence of accurate measurements of the size of the red cell precursors in some of the conditions.

It must be stated, moreover, that although, according to definition, anaemia is not macrocytic if the mean corpuscular volume is less than $95 \mathrm{cu}$. microns, a normal finding does not necessarily exclude megaloblastic anaemia. Megaloblasts may be found in the marrow, especially in the megaloblastic anaemia of pregnancy, even if the mean corpuscular volume is normal.

\section{Treatment of Megaloblastic Forms of Anaemia}

\section{Therapeutic Substances that are Available}

In treating patients with megaloblastic anaemia, the practitioner has the choice of using liver extracts, vitamin $B_{12}$, pteroylglutamic acid (usually referred to as folic acid), hogs' stomach preparations, proteolyzed liver or a combination of some of these substances.

Much progress has been made since Castle and his co-workers, in a series of papers, suggested that the anti-anaemic principle of liver was formed by the interaction of an extrinsic factor in food and an intrinsic factor normally secreted by the stomach. This provided an explanation for the development not only of pernicious anaemia but also of some of the other forms of megaloblastic anaemia. It was found, however, that not all megaloblastic anaemias would respond to liver injections. For this reason the introduction of proteolyzed liver by Davis et al. (1943) was an important step forward. Proteolyzed liver, a papain digest of whole liver, was found to produce a haematological response in forms megaloblastic anaemia such as "pernicious anaem of pregnancy,' which previously had defied all attempts at treatment other than by blood transfusion:

The synthesis of folic acid by Angier et (1945) made available a therapeutic weapon wifh great possibilities. Folic acid was found to produce a haematological and clinical response in the initial treatment of all forms of megaloblaste anaemia. Proteolyzed liver had a rather uf pleasant taste and varied in haemopoietic potency, but it was now possible to treat even the megatoblastic anaemia of pregnancy successfully witho a few milligrammes of folic acid in tablet form. It was found, too, that not only was the megafoblastic anaemia so commonly found in sprute benefited, but that the diarrhoea itself was in many cases improved without, however, aây coincidental improvement in fat absorption. of

The exact place of folic acid in relation fo Castle's theory was difficult to explain, but was certain that folic acid was neither the extrinsic factor nor the intrinsic factor.

The next development was the simultaneofs isolation from liver by Rickes et al. (1948) Merck's Laboratories in the United States nåd Lester Smith (1948) at Glaxo's laboratories th Great Britain of a highly potent anti-megalob astric substance which appeared to be the 'specific antianaemic factor.' For no very good reason this substance was given the name vitamin $B_{12}$, and was isolated in crystalline form both in the Unit: States and in Britain.

Castle and his co-workers (Berk et al., 19\%) produced evidence which suggested that not orgy did vitamin $B_{12}$ correspond to the anti-anaen factor but that vitamin $B_{12}$ or related substances also constituted the 'extrinsic factor.' This is now generally accepted and it is believed that the ra of the intrinsic factor is to promote the absorption of vitamin $B_{12}$ from the alimentary tract in some way as yet not understood. If vitamin $B_{12}$ is given by mouth to pernicious anaemia patients on amounts therapeutically effective when given po्fenterally, no haematological response occups, whereas if normal gastric juice is given simtaneously, there is the expected reticulocyte sponse and rise in the red cells. This is believ\&d to be because the intrinsic factor in the gasticic juice promotes the absorption of vitamin $B_{12}$. Nit has been shown (Ternberg and Eakin, 1949) that the intrinsic factor can enter into some form of combination with vitamin $B_{12}$ in vitro, but whether or not this actually occurs in a similar manner the body is uncertain. Recently it has been shown that liver contains another substance known os folinic acid or the citrovorum factor, which, too, is 
effective in the treatment of pernicious anaemia (Davidson and Girdwood, I95I). The name citrovorum factor is given because the substance, which is chemically related to folic acid, is necessary for the growth of a streptococcus named Leuconostoc citrovorum. This more recently discovered factor, like folic acid, is present only in minute quantities ( 0.2 to $0.5 \mu \mathrm{g}$. $/ \mathrm{ml}$.) in refined liver extracts, whereas the therapeutically active dose is measured in milligrammes. The therapeutic applications of the discovery of the citrovorum factor are still under investigation.

\section{The Interrelationships of the Antimegaloblastic Substances}

The metabolic interrelationships of these substances provides a difficult problem which cannot yet be answered. There is, as we have seen, widespread support for the view that vitamin $B_{12}$, perhaps together with some related forms, is the 'specific anti-anaemic factor.' Whether or not the small quantities of folic acid and folinic acid present in liver extracts can modify the therapeutic activity of vitamin $B_{12}$ has not been investigated.

The work of Nichol and Welch (1950) and of others suggests that it is likely that folic acid is first transformed to folinic acid in the body before it becomes an effective haematinic agent. If we accept this view, the two main theories at present available to explain the interrelationships of these factors are as follows:-

I. Folic acid is present in the food in a conjugate form which is haemopoietically inactive. After absorption, vitamin $B_{12}$ releases free folic acid from this conjugate form, thus:-

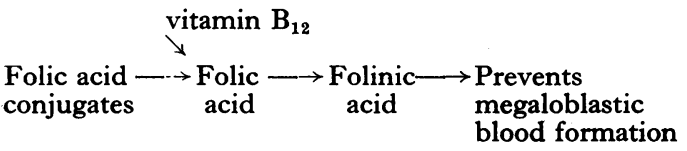

This theory was originally put forward because it was found that normal persons given the naturally occurring folic acid conjugate could excrete it as folic acid in the urine, whereas pernicious anaemia patients were unable to do so. Subsequent work showed that the interpretation of these findings was complicated by the occurrence of 'conjugase inhibitors' in the natural sources of the folic acid conjugate.

The main support for the theory now comes from the fact that although vitamin $B_{12}$ is effective only in certain types of megaloblastic anaemia folic acid is effective in all forms in the initial stages and converts megaloblastic blood formation to the normoblastic type.

The main objection is that pernicious anaemia patients maintained on folic acid frequently show. eventual haematological relapse.
2. The second theory, put forward by Vilter et al. (1950), is based largely upon bacteriological experiments. This theory suggests that folic acid and presumably folinic acid are coenzymes concerned with the formation of thymine from precursors such as uracil, and that vitamin $B_{12}$ is concerned with the formation of thymidine from thymine. From thymidine, nucleic acid. is derived.

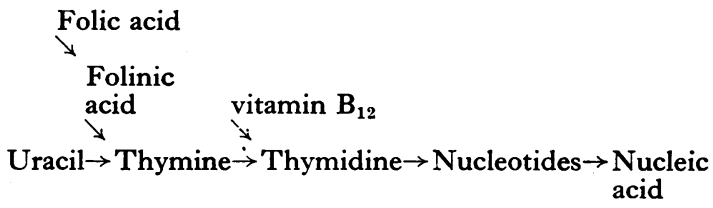

Vitamin $\mathrm{B}_{12}$ might fail to act in folic acid deficiency since the earlier stages of the metabolic process could not take place, and it is suggested that folic acid may be effective in the absence of vitamin $B_{12}$ by virtue of a 'mass action' effect.

This theory requires further investigation by therapeutic experiment.

In summary, it may be said that, at the moment, the interrelationships between these various haematological factors are uncertain, but that it is likely that vitamin $B_{12}$, folic acid and folinic acid are all required at some stage for normoblastic blood formation to continue.

\section{Various Forms of Vitamin $B_{12}$}

It has been shown that in addition to vitamin? $B_{12}$ itself, there are the forms vitamin $B_{12 b}$ (also known as $\left.B_{12 a}\right), B_{12 c}$ and $B_{12 d}$. The chemical formula of $B_{12}$ itself differs from that of the other forms in that a cyano group is present. All these forms are therapeutically active in pernicious anaemia.

Estimations of the vitamin $B_{12}$ content of tissues or fluids, including liver extracts, are usually done by microbiological assay methods, and the various forms of vitamin $B_{12}$ are now believed to differ in the extent to which they support the growth of the test organisms in such assays. If liver extracts are treated with sodium cyanide, however, the apparent vitamin $B_{12}$ content is often increased, and this is probably due to conversion of other forms to vitamin $B_{12}$ itself. It is thus possible for different workers to obtain very different results from their microbiological assays of liver extracts according to the technique that they use, and especially depending upon whether or not they first treat the liver extract with cyanide. We cannot, however, state with certainty that cyanide treatment does not free vitamin $B_{12}$ from forms that are therapeutically inactive, and it is possible that there are modifications or conjugates of vitamin $B_{12}$ that have not yet been identified. 
Table 2

Apparent Vitamin $B_{12}$ Content of Various Liver Extracts

\begin{tabular}{|c|c|c|c|}
\hline \multirow[b]{2}{*}{$\begin{array}{c}\text { Manufacturer } \\
\bullet\end{array}$} & \multirow[b]{2}{*}{$\begin{array}{c}\text { Date of } \\
\text { Manufacture }\end{array}$} & \multicolumn{2}{|c|}{ Vitamin $\mathrm{B}_{12}$ content (L. leichmannii assay) } \\
\hline & & $\begin{array}{c}\text { No cyanide added } \\
\mu \mathrm{g} . / \mathrm{ml} \text {. }\end{array}$ & $\begin{array}{c}\text { Cyanide added } \\
\mu \mathrm{g} . \mathrm{ml} \text {. }\end{array}$ \\
\hline $\begin{array}{c}\text { F } \\
\text { G } \\
\text { 2. Crude } \\
\text { Liver } \\
\text { Extracts: } \\
\text { A } \\
\text { E } \\
\text { G } \\
\text { H } \\
\end{array}$ & $\begin{array}{l}1945 \\
1946 \\
1948 \\
1949 \\
1950-51 \\
1950-51 \\
1950-51 \\
1945 \\
1946 \\
1947 \\
1947 \\
1947 \\
1948 \\
1950 \\
1950 \\
1950-51 \\
1950-51 \\
1950-51 \\
1950-51 \\
1948 \\
1949 \\
1950-51 \\
1950-51 \\
1947 \\
1950-51 \\
1950-51 \\
1950-51 \\
1950-51 \\
1948 \\
1950-51 \\
1950 \\
1950-51\end{array}$ & $\begin{array}{c}5.45 \\
1.25 \\
4.0 \\
7.6 \\
9.6 \\
10.4 \\
8.8 \\
2.7 \\
1.4 \\
2.1 \\
2.1 \\
0.9 \\
2.0 \\
3.7 \\
4.8 \\
5.2 \\
3.0 \\
5.8 \\
5.1 \\
0.25 \\
0.35 \\
4.3 \\
6.3 \\
1.7 \\
8.3 \\
10.4 \\
9.7 \\
9.3 \\
14.0 \\
7.4 \\
3.8 \\
11.0\end{array}$ & $\begin{array}{c}\bar{Z} \\
4.0 \\
13.8 \\
16.7 \\
11.4 \\
1.7 \\
1.4 \\
2.8 \\
4.2 \\
0.9 \\
= \\
7.3 \\
5.2 \\
5.9 \\
7.0 \\
6.2 \\
= \\
6.5 \\
14.3 \\
15.1 \\
16.7 \\
12.0 \\
14.2 \\
13.8 \\
3.8 \\
24.0\end{array}$ \\
\hline
\end{tabular}

Vitamin $B_{12}$ Content of Liver Extracts

In a previous paper (Girdwood and Carmichael, 1950) there was given the vitamin $B_{12}$ content of certain British liver extracts that had been manufactured between 1945 and 1950 . The work was done before the effects of adding cyanide to liver extracts was known, and hence the estimate made was probably chiefly that of vitamin $B_{12}$ itself. In most instances the content was low, and although statistical evaluation of the response to therapy in pernicious anaemia is only of limited value, it can be said that there was no evidence from this method of approach to suggest that the therapeutic activity of the liver extracts tested could not be explained on their vitamin $B_{12}$ content.
More recently, by the kindness of the man facturers concerned, it has been possible to assiy several batches of liver extract produced in 1950 and I95I, and to repeat the assay after treatirg the extracts with cyanide. Some of the resulfs have already been published (Girdwood, I95 0 , but in Table 2 the earlier results are compared with the more recent ones and, in addition, it has been found possible to include in a few instances $\mathrm{rg}^{2}$ peats of the earlier assays after the addition of cyanide. It will be seen that cyanide treatmeat did not make a very great difference to the ẩparent vitamin $B_{12}$ content of some extraces, whereas in others the difference was considerable This is no doubt due in part to variations in manu- 
facturing technique leading to differences in the forms of vitamin $B_{12}$ present in the resulting liver extract.

The argument that the therapeutic activity of liver extracts can be explained on their vitamin $B_{12}$ content is merely strengthened by the new development in assay technique.

\section{The Place of Folic Acid in the Therapy of the Megaloblastic Anaemias}

The first great hopes about the future of folic acid in the treatment of the megaloblastic anaemias were dashed when it was found that folic acid would not prevent the neurological complications of pernicious anaemia, and in fact appeared to precipitate them. For this reason the use of folic acid must be restricted to the other forms of megaloblastic anaemia where subacute combined degeneration of the cord is very rarely seen. as a complication.

Folic acid does not give rise to neurological disorder in normal persons, or in patients suffering from other forms of anaemia, and there is no evidence that it will produce subacute combined degeneration of the cord if it is given in the usual dosage to pernicious anaemia patients receiving adequate treatment with vitamin $B_{12}$ or liver extracts. On the other hand, there is no evidence that folic acid has any beneficial effect in such cases, and accordingly there is no point in using it in conjunction with vitamin $B_{12}$ in pernicious anaemia. In the other forms of megaloblastic anaemia, however, there is a definite place for folic acid therapy.

The reason for the acute onset of neurological complications when pernicious anaemia is treated with folic acid is not obvious. The acuteness of this development in many cases suggests that it is more than a matter of giving something that produces haematological improvement without preventing the natural course of neurological complications. Other suggestions that have been made are that folic acid has a toxic effect on the nervous system in itself (but we have seen that folic acid does not produce neurological complications in normal persons) that an 'imbalance of vitamins' is produced when folic acid is given, or that traces of vitamin $B_{12}$ remaining in the body may be used up when folic acid produces a haemopoietic response by a 'mass action' effect. Davidson (1947) has suggested that subacute combined degeneration of the cord is normally prevented by some substance other than folic acid that exists in a conjugate form and from which it may be released or made available in some way by vitamin $\mathrm{B}_{12}$.

When folic acid is used therapeutically it is probably best to use tablets of the substance since folic acid may lose its activity in solution if exposed to light.

\section{The Use of Hogs' Stomach Preparations}

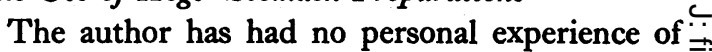
the use of such preparations, which are expensive $\stackrel{5}{9}$ and less easy for the patient to take, but Wilkinson 0 (1949) reports satisfactory results with this form 음 of therapy in pernicious anaemia. The dose is $\frac{\bar{m}}{\vec{b}}$ $\frac{1}{4}$ to $\mathrm{I}$ oz. daily.

It is possible that such extracts are active when given orally because they contain both intrinsic factor and vitamin $B_{12}$, the former promoting the ? absorption of the latter (Bethell et al., 1949). $\vec{\omega}$

Bethell, too, working in conjunction with the Upjohn Company of Kalamazoo, Michigan, has 8 prepared extracts of hogs' duodena and vitamin 3 $B_{12}$ that are active when given by mouth. It is doubtful whether such preparations have any $\dot{\omega}$ practical advantage since they are no more effec- $\vec{\omega}$ tive than liver extracts or vitamin $B_{12}$, and in $f$ addition the pernicious anaemia patient may feel 6 tempted to be erratic in taking oral remedies when feeling well. As a result, irreversible neurological complications may develop.

\section{Proteolyzed Liver}

The indications for proteolyzed liver preparaे tions are now very limited, since folic acid table are so much more convenient to take. Accordin of to the information supplied by one of the firms marketing proteolyzed liver, $\mathbf{I} \mathrm{oz}$. of the preparation (a daily dosage that should be satisfactory for initial treatment) contains approximately $1 \mathrm{mg}$. of folic acid and $300 \mu \mathrm{g}$. of vitamin $B_{12}$. Although $\stackrel{\circ}{\varnothing}$ details are not given, the usual method of assay of $\varrho$ folic acid is such that it is likely that any folinic acid present is included as folic acid. The therapeutic activity of proteolyzed liver is no doubt due to its content of these substances, although it may be that other unknown factors with an antimegaloblastic effect are present. Should this be so there may be some place for proteolyzed liver in the treatment of patients with the sprue syndrome who cease to show a haematological response to folic acid.

The Management of a Case of Pernicious Anaemia

It is important to be sure that the patient does, in fact, suffer from pernicious anaemia, and the $\tilde{N}$ appearance of blunderbuss forms of therapy for $N$ the anaemias, consisting of tablets or capsules $N$ containing a mixture of iron, folic acid, hogs' stomach, etc., cannot be too strongly condemned.

For practical purposes the choice lies between the use of vitamin $B_{12}$ and of refined liver extracts given parenterally. Vitamin $B_{12}$ has been prepared from various sources, including liver, the

\section{.}


culture fluid of Streptomyces griseus and of Streptomyces aureofaciens, from a motile bacillus found in hens' faeces, and from horse manure. Satisfactory clinical responses have been obtained from these various preparations.

For the initial treatment, vitamin $B_{12}$, which now may be obtained in ampoules containing 10 , 20,50 or $100 \mu \mathrm{g} . / \mathrm{ml}$., may be given in a dosage of the order of $50 \mu \mathrm{g}$. weekly until the red cell count is normal. The optimal dosage of any liver extract must depend upon its vitamin $B_{12}$ content, but with a refined extract produced by a reputable firm, $4 \mathrm{ml}$. given twice in the first week and $4 \mathrm{ml}$. given weekly until the red cell count is normal, should suffice.

If the anaemia is very severe, the red cell count being one million per cmm. or less, or the patient's general condition precarious; blood transfusion may be necessary The patient's general condition will depend to a certain extent on the speed with which the blood level is falling. Usually cells from one pint of blood are given very slowly. Anaemia may give rise to cardiac failure with raised venous and right auricular pressure, and a further rise in filling pressure on the right side of the heart may lead to a fall in cardiac output. Pulmonary oedema may result.

For this reason, if transfusion is given, the veins in the neck should be examined carefully for evidence of raised venous pressure. Digoxin, which may reduce venous pressure, may be given intravenously.

If subacute combined degeneration of the cord is present it is wise to give large doses of vitamin $B_{12}$, and roo $\mu$ g. to $200 \mu \mathrm{g}$. may be administered weekly during the first six months of treatment. If liver injections are given, refined liver extracts should be used, since they contain more vitamin $B_{12}$. There is no satisfactory evidence that the crude extracts are more beneficial than the refined ones in the treatment of subacute combined degeneration of the cord. Where the neurological features are only those of paraesthesiae, recovery may be guaranteed; where there is evidence of posterior column involvement the chances of complete recovery are good; but where there are signs of lesions of the pyramidal tracts, especially if they are of long duration, the prognosis is very poor. However, there have been numerous reports of a marked improvement following the administration of vitamin $B_{12}$ or of refined liver extracts even where the plantar responses were dorsiflexor. Re-educative exercises are of great value.

It is not uncommon for iron deficiency to develop during the first few weeks of treatment of pernicious anaemia, and this should be treated with ferrous sulphate, 3 to 6 gr. t.i.d., or ferri and ammonium citrate, 30 gr. t.i.d.
The marrow changes from the megaloblastic to the normoblastic state very rapidly when vitamin $B_{12}$ or liver extract is given, striking changes being found as early as six hours after the commencement of treatment. On the other hand, reversion to the $\stackrel{ }{\Rightarrow}$ abnormal state may also be relatively rapid and $\stackrel{\vec{\rho}}{+}$ Mollin and Dacie (1950) have found some re- $\bar{c}$ version to megaloblastic blood formation as soon as I I days after a small dose of vitamin $B_{12}$.

The examination of a bone marrow film two or $\stackrel{\mathbb{Q}}{\alpha}$

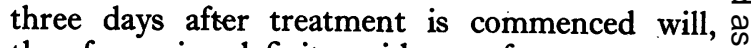
therefore, give definite evidence of a response to $\rightarrow$ therapy. Such a response is often obvious clinically even at this early stage from the improvement $\vec{\omega}$ in the patient's appetite and sense of well being, $\stackrel{\circ}{\circ}$ and the return of a pink colour to the cheeks. The $\overparen{D}$ reticulocyte count in the peripheral blood should 3 be followed, although in other forms of megalo- iv blastic anaemia a reticulocyte response is some- $\dot{\omega}$ times seen without a corresponding improvement $\vec{\omega}$ in the red cell level and, conversely, a very satis- of factory red cell rise may be found without the occurrence of the expected reticulocyte peak. Ungley and Campbell (1949), using a vitamin $B_{12}$ preparation, have given a formula for predicting the expected red cell rise at the ${ }_{1} 5^{\text {th }}$ day of treatment following single injections of vitamin $B_{12}$ og varying amounts. If desired, the patient's re sponse may be compared with the predicte $\vec{\theta}$ response according to the formula of Ungley and. Campbell.

\section{Maintenance Therapy}

As yet there is little published work on the maintenance therapy of pernicious anaemia patients with vitamin $\mathrm{B}_{12}$. Meacham et al. (1950) were unable to maintain the red cells at a satisfactory level with $20 \mu \mathrm{g}$. every three weeks, whereas Girdwood (I95I) had satisfactory results using 40ug. every two to three weeks. Vitamin $B_{12}$ is rapidly excreted in the urine, although it is possible that it circulates in the blood in a "combined' form (Ross (I95I) for several weeks. It seems that a satisfactory dosage for maintenance therapy is 40 to $50 \mu \mathrm{g}$. every three weeks. Whether or not $100 \mu \mathrm{g}$. every four weeks will be equally satisfactory has not yet been established.

As regards maintenance with refined liver extracts given parenterally, it is not yet quite certain whether or not the activity of such extracts can be explained on their vitamin $B_{12}$ content alone. This can only be established if satisfactorily controlled tests are carried out using on alternate patients a vitamin $B_{12}$ preparation and a liver extract of similar vitamin $B_{12}$ content, and here again we are faced with the difficulty of deciding exactly what is the true vitamin $B_{12}$ content of a particular liver extract. 
The author has not been able to maintain the red cell count consistently at an entirely satisfactory level with $4 \mathrm{ml}$. of certain refined liver preparations given monthly, although the patients felt well and developed no neurological complications.

\section{Sensitivity to Liver Extracts}

Certain patients develop features of sensitivity, such as fever rigors or a rash when injected with liver extracts. Such patients can almost always tolerate injections of vitamin $B_{12}$ without any difficulty, especially if a crystalline preparation is used. Such preparations are now freely available.

\section{Macrocytic Anaemia in Steatorrhoea}

It is uncommon for patients with coeliac disease to have anything other than iron deficiency anaemia, although a megaloblastic form occasionally occurs. In idiopathic steatorrhoea and in tropical sprue, however, a megaloblastic form of anaemia is not uncommon, and sometimes there is found to be a macrocytic anaemia associated with the presence of cells intermediate between megaloblasts and rormoblasts, to which we have already referred.

Some sprue patients with megaloblastic anaemia show a response to vitamin $B_{12}$ whereas others fail to respond to this, but all show an initial haematological improvement when treated with folic acid by mouth or by injection. One possible explanation is that in some instances there is malabsorption of vitamin $B_{12}$, whereas in other patients the defect is in absorption of folic acid and conjugates. This, however, is not the whole story, since haematological relapse may occur during maintenance treatment with folic acid and because the form of macrocytic anaemia that is not associated with a frankly megaloblastic marrow will not usually respond to folic acid. Whether there is some other haematinic principle missing, whether it is folinic acid, and whether the hypothetical missing substance is present in proteolyzed liver, has not yet been established. Nor do we know why folic acid may sometimes control the diarrhoea without at the same time affecting the percentage absorption of fat.

From the practical point of view, the megaloblastic anaemia associated with steatorrhoea should be treated with folic acid by mouth in a dosage of ro to $20 \mathrm{mg}$. daily. At the same time the patient must be treated for steatorrhoea and for other deficiencies in the usual manner. In a severe case, dietetic restrictions may have to be severe, especially in the early stages of treatment, but patients should be encouraged to take as much fat as they can tolerate, since an increase of dietary fat does not reduce the percentage of fat absorbed.
Every patient with the sprue syndrome is an individual problem, and if folic acid therapy alone fails or is not fully efficacious either in the treatment of a macrocytic blood picture or in the control of diarrhoea, then dietetic restrictions may be increased, vitamin $B_{12}$ may be tried in a dosage of 5 oug. weekly, or liver injections (e.g. $4 \mathrm{ml}$. of a refined liver extract weekly) may be given. Alternatively, the use of proteolyzed liver merits a trial. There are some patients with steatorrhoea who maintain emphatically that they derive benefit only from one particular brand of liver extract, sometimes a crude extract with a very low vitamin $B_{12}$ content and negligible content of folic acid and folinic acid. The psychological factor plays a large part in many cases of steatorrhoea, and is responsible for some statements of this nature. Nevertheless a controlled study of the therapeutic value of the different forms of liver extract would be of interest.

\section{Megaloblastic Anaemia of Pregnancy and the Puerperium}

For reasons that are not at all obvious, megaloblastic anaemia may occur in pregnancy, or may not be recognized until after delivery. In tropical regions, the condition is probably due in part to primary malnutrition, but Bethell et al. (1939) working in the northern parts of the United Stateso $\overrightarrow{0}$ have shown an inverse relationship between the of incidence of macrocytic anaemia of pregnancy an $\$$ the animal protein content of the diet. Goldhamer et al. (1939) found that even severe forms of the disorder could be treated by the addition of protein to the diet.

Our clinical impression here is that dietary deficiency is not of primary importance in the pathogenesis of megaloblastic anaemia of pregnancy, and that the condition cannot usually be treated by purely dietetic means. The feeding of I lb. or more of liver daily might produce improvement because of the folic acid supplied (probably about $\mathrm{r}$ to $3 \mathrm{mg}$. daily), but we have no information about the therapeutic efficiency of folic acid conjugates in the treatment of the condition.

If the anaemia is very severe, blood transfusion should be given slowly. As yet there have been no reports from temperate climates of a satisfactory response to. vitamin $B_{12}$, and no recorded failures with folic acid therapy. Accordingly, folic acid should be given in a dosage of $20 \mathrm{mg}$. by mouth daily. This dosage may be continued, or reduced after three or four weeks to ro mg., the administration of folic acid being continued in the puerperium until the red cell level has been normal for a month. Iron therapy will doubtless also be required.

Thereafter the patient should have the blood 
checked from time to time for a period of a year, and during subsequent pregnancies. The condition does not necessarily recur.

There is some evidence to suggest that patients who have pernicious anaemia complicated by pregnancy may become temporarily refractory to liver therapy during childbirth (Davidson et al., 1948). If this occurs, folic acid therapy may have to be given as a temporary measure.

\section{Nutritional Macrocytic Anaemia}

Whether an aetiological or a morphological classification is adopted, there is no doubt that various forms of nutritional macrocytic anaemia occur. It is possible that there are geographical variations in the types of the disorder, and the matter is made more complex by complicating factors such as pregnancy, dysentery, steatorrhoea, hookworm infestation and malaria. Truly megaloblastic forms of the disease will always respond to folic acid therapy. Sometimes there is a response to vitamin $B_{12}$ therapy, but as yet there have been no reports of cases that responded to vitamin $B_{12}$ but not to folic acid.

Since macrocytic anaemia due to primary malnutrition is almost unknown in Britain, the condition will not be considered further, and for the same reason the treatment of megaloblastic anaemia in infancy and the form due to diphyllobothrium latum infection will not be considered.

\section{Idiopathic Refractory Megaloblastic Anaemia}

The condition of idiopathic refractory megaloblastic anaemia as described by Davis and Davidson (1944) is probably the same as achrestic anaemia as now defined by Wilkinson (1949). These terms were first applied to forms of megaloblastic anaemia for which no cause was obvious and which failed to respond to refined liver extracts. Sometimes free hydrochloric acid was present in the gastric juice. Before such a diagnosis was made it was important to be sure that potent liver extracts were used in treatment, and now vitamin $B_{12}$ is available to obviate any question of lack of potency of the therapeutic agents employed.

The condition responds to folic acid therapy, and it has been found that some such patients later develop clinical features of the sprue syndrome and that others have evidence of gastric carcinoma.

Treatment of Forms of Macrocytic Anaemia where the Marrow is Not Usually Megaloblastic

\section{Cirrhosis of the Liver}

It is generally considered that macrocytic anaemia occurs in hepatic cirrhosis only if the cirrhosis is severe. However, Berman et al. (1949) found no correlation between the severity of the anaemia and the degree of cirrhosis as established by liver biopsy. This may, however, merely b $\mathrm{g}$ an indication of the inadequacy of liver biopsy. methods. The same authors found that of 2 cases, 21 had anaemia and 16 showed macrocytosis? The marrow was macronormoblastic and neve? megaloblastic.

The occurrence of a true megaloblastic anaemia in association with cirrhosis is probably rare, an\& some deny its occurrence, but Movitt (1950) haš described three cases, one of which was treated successfully with vitamin $B_{12}$. The commoner macronormoblastic form does not respond to foli६ acid or vitamin $B_{12}$.

\section{Renal Disease}

Dameshek (1935) and numerous other writeris have described hypoplasia of the marrow in chronic renal disease. Recently, however, Cullen and Limarzi (1950) have studied 72 patients witkj renal disease, 44 of whom had a non-proteine nitrogen level of more than $40 \mathrm{mg}$. per cent. The mean corpuscular volume in these 72 patients varied from 63 to $102 \mathrm{cu}$. microns, and eighb patients had a macrocytic anaemia. The anaemie patients all suffered from azotaemia, but ond where the non-protein nitrogen exceeded $150 \mathrm{mg}$ per cent. was there evidence of hypoplasia.

There is no specific treatment for the anaen itself.

\section{Scurvy}

The anaemia of scurvy is occasionally macrocytic (Vilter and Woolford, 1945), and will re-0 spond to the administration of ascorbic acid. IB iron deficiency is also present, ferrous sulphate of ferri and ammonium citrate should be given.

\section{Myxoedema}

Recently Axelrod and Berman (195I) have in vestigated the marrow picture in nine patients with myxoedema and have concluded that there is:definite hypocellularity of the marrow. They suggest that hypothyroidism should always be considered in any patient having a hypocellular marrow with macrocytic anaemia. Bomford (1938) and others have described a megaloblastig type of anaemia in some cases of myxoedema‥ possibly due to an associated Addisonian pernicious anaemia. In the latter form vitamin $B_{12}$ therapy will be required in addition to the administration of thyroid extract, but in the usual form of macrow cytic anaemia of myxoedema itself, there will be response to thyroid alone.

\section{The Haemolytic Anaemias}

A full consideration of the various forms of haemolytic anaemia and of the validity of state 
ments about the size of the red cells in these types would in itself constitute material for an article longer than the present one. Macrocytosis may occur where the reticulocyte count is high, but it may be found even without this.

The types of haemolytic anaemia occurring in this country in which macrocytosis may be found include acute idiopathic haemolytic anaemia (Lederer's anaemia), chronic idiopathic haemolytic anaemia (acquired haemolytic anaemia), and haemolytic anaemic symptomatic of diseases such as chronic lymphatic leukaemia and lymphosarcoma. Sometimes macrocytosis rather than the usual microspherocytosis occurs in congenital haemolytic icterus.

There is no doubt that splenectomy should be carried out in congenital haemolytic icterus if the anaemia is severe or associated with repeated crises, or if the efficiency of the patient is impaired. If possible this should be done during a remission, careful blood transfusion being given if necessary. It is important that gallstones should be looked for and removed and that a search should be made for spleniculi. Unless crises occur, the spleen should not be removed in children under the age of ten years. There is no evidence of a beneficial effect of ACTH in the congenital form of the disorder?

In Lederer's anaemia, blood transfusion is usually successful, but sometimes splenectomy is required. In chronic idiopathic haemolytic anaemia, a condition which is probably due to the presence of haemolysins, splenectomy may beo successful. Recently there have been reports of음 remissions which appeared to be the result of ACTH therapy in this condition and in cases of symptomatic haemolytic anaemia (Davidson et al. 0 I95 I; Dameshek et al., 195I). Further time must? elapse before we can assess the true place of this 0 new form of therapy which may prove to be of value in certain instances in preparing patients foro splenectomy.

\section{Other Forms of Macrocytic Anaemia}

In idiopathic aplastic anaemia and in osteo it sclerosis, blood transfusion will be necessary. Thछ administration of vitamin $B_{12}$ and folic acid mayis be tried although there is unlikely to be a responseso In other forms of macrocytic anaemia that have nof been considered the treatment is that of the causative condition together with transfusion.

\section{BIBLIOGRAPHY}

ANGIER, R. B., et al. (1945), Science, 102, 227.

AXELROD A. R., and BERMAN, L. (195I), Blood, 6, 436.

BERK, L., CASTLE, W. B., WELCH, A. D., HEINLE, R. W., ANKẺE, R., and EPS'TËIN, M. (1948), Në Eng. Fourn. Med., 239 oI I.

BERMAN L., AXELROD, A. R., HORAN, T. N., JACOBSON, S. D., SHARP, E. A., and V̈ONDER HEIDE, F. C. (1949), Blood, 4, 511.

BETHELL, F. H., GARDINER, S. H., and MACKINNON, F. (1939), Ann. Int. Med., 13, 91.

BETHELL, F. H., SWENDSEID, M. E. MEYERS, M. C., NELIGH, R. B., RICHARDS, H. G. (1949): Univ. Hosp. Bull., Univ. of Michigan, 15, 49.

BOMFORD, R. R. (1938), Quart. F. Med., 7, 495.

CULLEN, I. R., and LIMARZI, L. R. (1950), Am. F. Clin. Path., 20, 3.

DACIE, J. V., and WHITE, J. C. (1949), F. Clin. Path., 2 , I.

DAMESHEK, W. (1935), Am. F. Med. Sci., 190, 617.

DAMESHEK, W., ROSENTHAL, C., and SCHWARTZ, L. I. (195I), New Eng. Fourn. Med., 244, 117.

DAMESHEK, W., and SCHWARTZ, S. O. (1940), Medicine, I9, 231 .

DAVIDSON, L. S. P. (1947), personal communication.

DAVIDSON, L. S. P., DUTHIE, J. J. R., GIRDWOOD, R. H., and SINCLAIR, R. J. G. (1951), Brit. Med. F., i, 657.

DAVIDSON, L. S. P., and GIRDWOOD, R. H. (1951), Lancet, i, 722.

DAVIDSON, L. S. P., GIRDWOOD, R. H., and CLARK, J. R. (1948), Brit. Med. F., i, 819.

DAVIS, L. J., and DAVIDSON, L. S. P. (1944), Quart. F. Med., 13, 53.

DAVIS, L. J., DAVIDSON, L. S. P., RIDING, D., and SHAW, G. E. (I943), Brit. Med.. ., i, 655 .

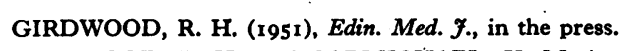

GIRDWOOD, R. H., and CARMICHAEL, K. M. (1950), Med. F., i1, 1357 . MOd. F., I1, I357.
GOL. (I939), F. Clin. Invest., 14, 481.

ISRAELS, M. C. G. (1939), Y. Path. Bact., 49, 23 I.

.ISRAELS, M. C. G. (194I), Lancet, ii, 207.

MEACHAM, G. C., VIGNOS, P. J., HEINLE, R. W., WEIS

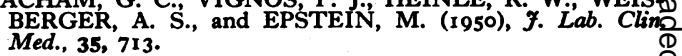

MOLLIN, D. L., and DACIE, J. V. (1950), Proc. Roy. Soc. Med. 은 43, $54 \mathrm{I}$.

MOVITT, E. R. (1950), Blood, 5, 468.

NICHOL, C. A., and WELCH, A. D. (1950), Proc. Soc. Exptal. Biol. Med., 74, 403.

RICKES, E. L., BRINK, N. G., KONIUSZY, F. R., WOODO T. R., and FOLKERS, K. (I948), Science, 107, 396.

ROSS, G. I. M. (1950), Nature, 166, 270.

SMITH, E. L. (1948), Nature, 161, 638.

TERNBERG, J. L., EAKIN, R. E. (1949), f. Am. Chem. Soc. 7I, 3858 .

UNGLEY, C. C., and CAMPBELL, H. (1949), Brit. Med. F. ii, 1370 .

VILTER, R. W., HORRIGAN, D., MUELLER, J. F., JARROLD T., VILTËR, C. F., HAWKINS, V., and SEAMAN, AS (1950), Blood, 5, 695. VILTER, R. W., and WOOLFORD, R. M. (1945), F. Lab. Cling
Med., 30, 388.

WHITBY, L., and BRITTON, C. J. C. (1950), 'Disorders of the Blood,' 6 th edition, J. and A. Churchill Ltd., London. WILKINSON, I. F (1949), Lancet, i, 292. 